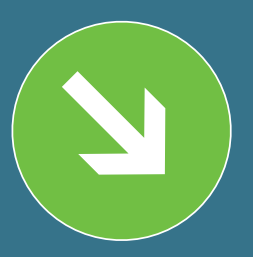

\title{
СТАНКИ ДЛЯ ПОВЫШЕНИЯ ЭФФЕКТИВНОСТИ УЧАСТКОВ ГЛУБОКОЙ ПЕРЕРАБОТКИ
} ДРЕВЕСИНЫ

\author{
Григорий ильин
}

От эффективности производства зависит его выживаемость. А на его эффективность прежде всего влияет использование современного оборудования, внедряемого на передовых производствах.

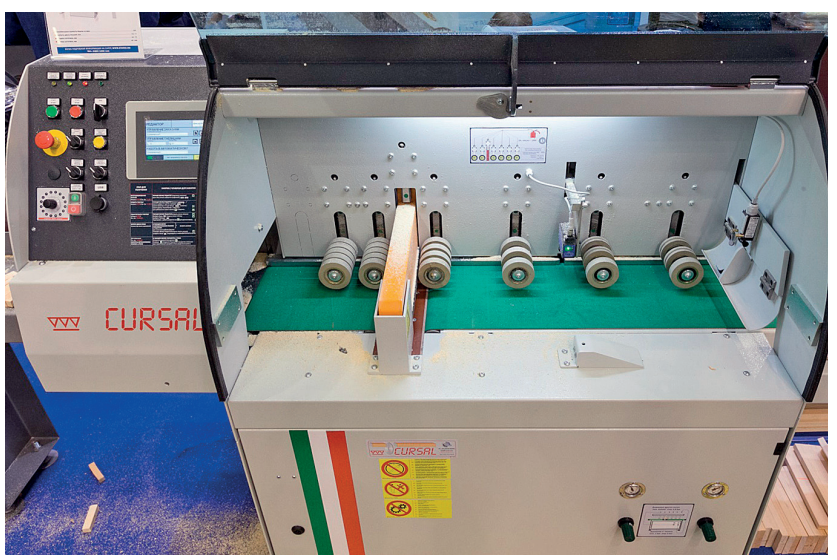

Одной из ключевых проблем 2018 года для деревообработчиков стала автоматизация и оптимизация участков глубокой переработки древесины. В русле мировых тенденций идет сокращение рабочей силы, на замену приходят новые машины, новая механизация, новые технологии. На рынке растет конкуренция, поэтому стремление получить продукцию более высокого качества и снизить себестоимость - это темы, которые затрагивались в течение всего года и присутствовали во всех обсуждениях.

Для того чтобы иметь возможность обсудить насущные потребности наших заказчиков, Ассоциация КАМИ ежегодно участвует во всех основных деревообрабатывающих выставках. Конечно же, главная площадка для проведения переговоров это выставка «Лесдревмаш», которая состоялась в конце 2018 года. Особый интерес на выставке вызвали линии оптимизации и оборудование для сращивания. Эта тема была интересна как начинающим деревообработчикам, желающим получить максимальный выход от вложенных денег, так и тем, кто уже давно работает и понимает, что модернизация неизбежна.

Линия оптимизации вырезает дефектные места в заготовке (сучки, трещины, смоляные карманы и т.д.) и торцует заготовку на заданные оператором размеры.

Линия сращивания позволяет сращивать заготовки разной длины, получаемые в оптимизаторе, в единую (доску) плеть.

Преимущества использования линии оптимизации и сра- 
щивания на деревообрабатывающем производстве заключается в том, что, используя в технологии линии оптимизации и сращивания, производство выйдет на новый уровень: снизится себестоимость продукции, повысится объем полезного выхода, будут исключены ошибки работников, обеспечена безопасность работы и снижены трудозатраты.

Эффект от внедрения достигается за счет следующих факторов:

$\rightarrow$ увеличения выхода
полезной продукции до 15-20\% за счет вырезки необходимых дефект-

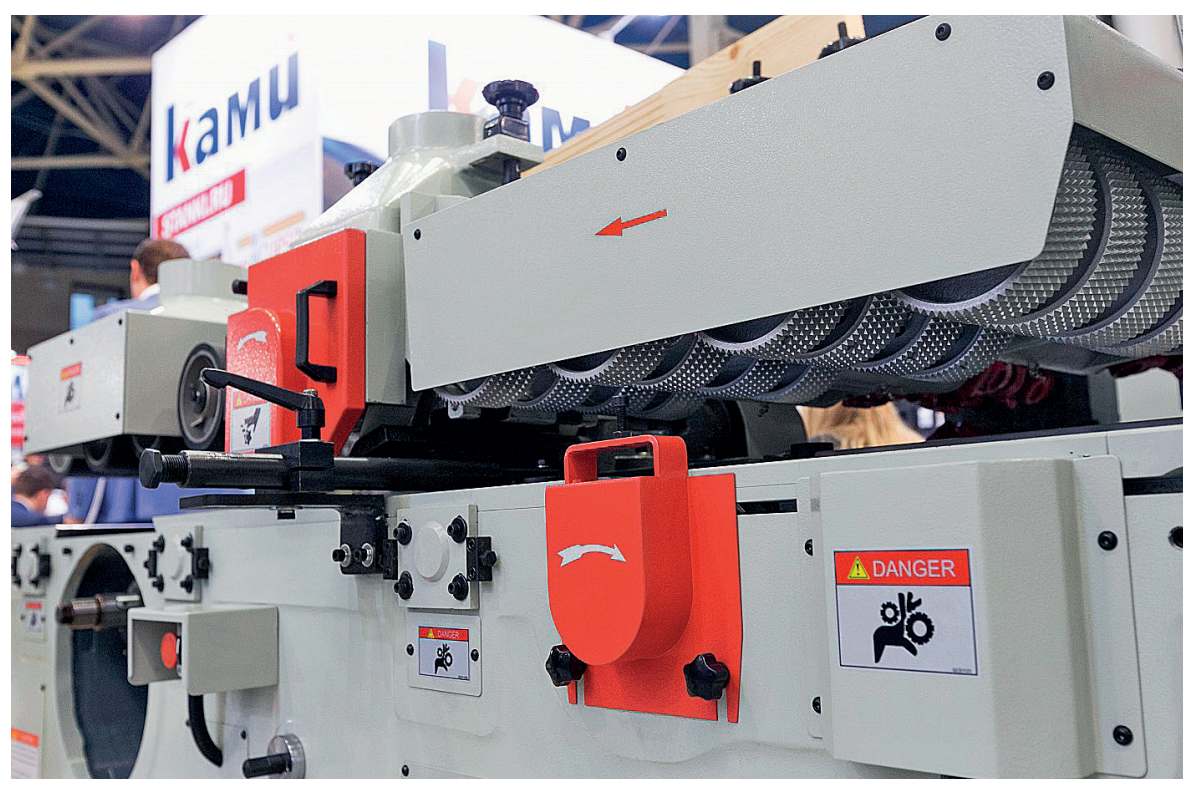
ных мест и вырезки из полезных длин, необходимых для нужд производств;

$\rightarrow$ увеличения производительности за счет высокой скорости резания и подачи материала, возможна замена до 6-10 человек на этом участке;

$\rightarrow$ упрощенной логистики в цехе - при сортировке материала на выходе из торцовочного станка;

$\rightarrow$ ведения статистики по учету входного и выходного материала;

$\rightarrow$ определения более качественного поставщика леса / пиломатериала;

$\rightarrow$ ведения статистики и учета рабочего времени цеха: в смену, неделю, месяц, квартал, год.

Линии оптимизации и сращивания оказались наиболее востребованы в производстве клееного щита, где новинкой на рынке также выступил двусторонний рейсмус с пильным валом. Станок выполняет сразу две операции обработки, которые «по старинке» производились на многопильном станке и 4-стороннем станке. Это позволяет достичь огромной экономии во вложенных деньгах, персонале, внутрицеховом месте, инструменте, припусках на заготовке, энергозатратах.

Предприятия, на которых установлено оборудование данного типа, динамично развиваются и имеют лучшее качество продукции при минимальной себестоимости. Для Ассоциации КАМИ важно иметь именно таких партнеров, так как шагать в ногу со временем всегда лучше вместе, одновременно достигая высоких результатов.

ильин Григорий -

руководитель отдела глубокой переработки древесины Ассоциации «КАМИ»
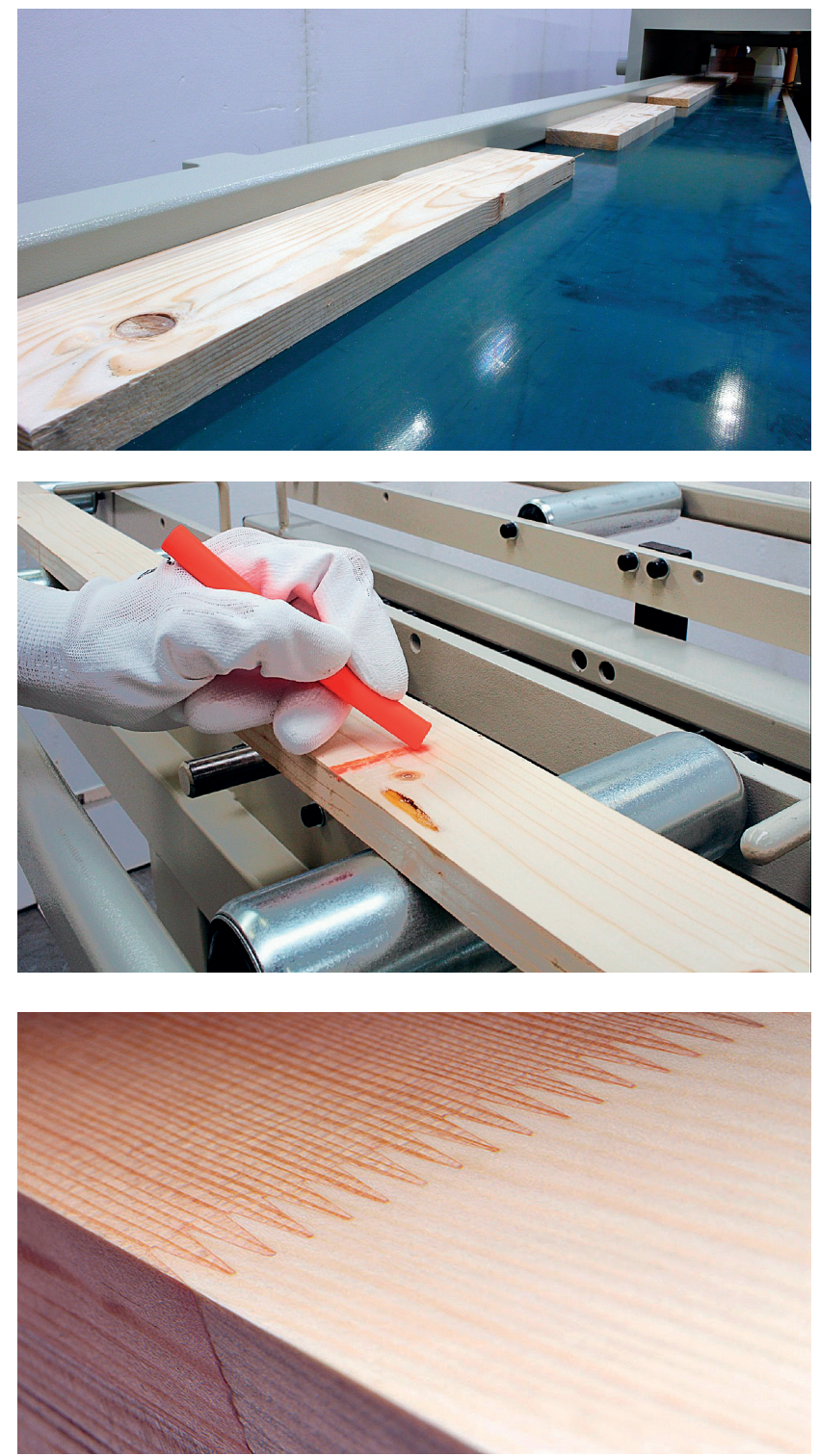